\title{
Kimura's Disease-A Rare Cause of Postauricular Swelling: A Case Report from the Hilly Region
}

\author{
Trilok C. Guleria, MBBS, MS ${ }^{1}$ Mahender Singh, MBBS, MS ${ }^{2}$ Vishal Singh, MBBS, MS 3 \\ Ramesh K. Azad, MBBS, MS² Narender K. Mohindroo, MBBS, $\mathrm{MS}^{2}$
}

\footnotetext{
1 Department of Otolaryngology-Head and Neck Surgery, Dr Radhakrishnan Govt. Medical College, Hamirpur, Himachal Pradesh, India

2 Department of Otolaryngology-Head and Neck Surgery, Indira Gandhi Medical College, Shimla, Himachal Pradesh, India

${ }^{3}$ Department of Otolaryngology-Head and Neck Surgery, Dr. Rajendra Prasad Govt. Medical College, Tanda, Himachal Pradesh, India
}

Surg J (NY) 2022;8:e19-e21.

\author{
Address for correspondence Trilok C. Guleria, MBBS, MS, Department \\ of Otolaryngology-Head and Neck Surgery, Dr Radhakrishnan Govt. \\ Medical College, Hamirpur, Himachal Pradesh 177001, India \\ (e-mail: tcguleria@gmail.com).
}
Abstract
Keywords
- chronic
- postauricular
- eosinophilia
- lymphadenopathy
$-\lg \mathrm{E}$

Kimura's disease (KD) is a chronic inflammatory disorder of the lymph node which is very rare in the Indian population. A 34-year-old female presented with left postauricular region swelling for the past 3 years at an outpatient department. On histopathological examination, it was diagnosed as KD. It should be kept in mind when treating a patient with lymphadenopathy and eosinophilia or a high immunoglobulin E level. This unique case report highlights this impressive clinical entity.

Kimura's disease (KD) was first described by Kim and Szetu in 1937 as an eosinophilic hyperplastic lymphogranuloma. The disease was known as KD since it was described by Kimura et al in 1948 in a manuscript titled "On the Unusual Granulation Combined with Hyperplastic Changes of Lymphatic Tissue. ${ }^{1,2}$ It is endemic in Japan and China but sporadic cases have been reported worldwide. ${ }^{3}$

KD is rare in India, with approximately 200 reported cases worldwide since its histopathological diagnosis. ${ }^{4}$ The disease is characterized by the triad of painless subcutaneous masses, peripheral eosinophilia, and increased immunoglobulin (Ig) E levels. Recent studies have shown that KD occasionally shows the clonal proliferation of Tcells. $^{5}$ The diagnosis of KD is often difficult, and biopsy/excision of involved mass is necessary. Early and timely diagnosis of KD can avoid the unnecessary and expensive invasive diagnostic procedure, as it may mimic a neoplastic condition.

received

October 7, 2021

accepted after revision

December 3, 2021

\section{Case Report}

A 34-year-old female presented to the ear, nose, and throat outpatient department for left-sided postauricular swelling for 3 years. There was no history of fever, any other swelling in the body, ear discharge, scalp infection, or weight loss. On local examination, swelling of size, $4 \mathrm{~cm} \times 3 \mathrm{~cm}$ was present in the left postauricular area which was nontender, firm, nonfluctuant with normal skin overlying (- Fig. 1).

Peripheral blood smear showed 20\% eosinophils. Renal function tests were within normal limits and there was no evidence of proteinuria. Chest radiograph was also within normal limits. Fine-needle aspiration cytology was suggestive of nonspecific reactive hyperplasia. Because of concern that the mass might be some lymphoproliferative disorder or neoplasm, an excision biopsy was taken. Histopathological examination of the mass showed fibromuscular tissue with interspersed lobules of the polymorphous population of

\section{(c) 2022. The Author(s).}

This is an open access article published by Thieme under the terms of the Creative Commons Attribution License, permitting unrestricted use, distribution, and reproduction so long as the original work is properly cited. (https://creativecommons.org/licenses/by/4.0/)

Thieme Medical Publishers, Inc., 333 Seventh Avenue, 18th Floor, New York, NY 10001, USA 


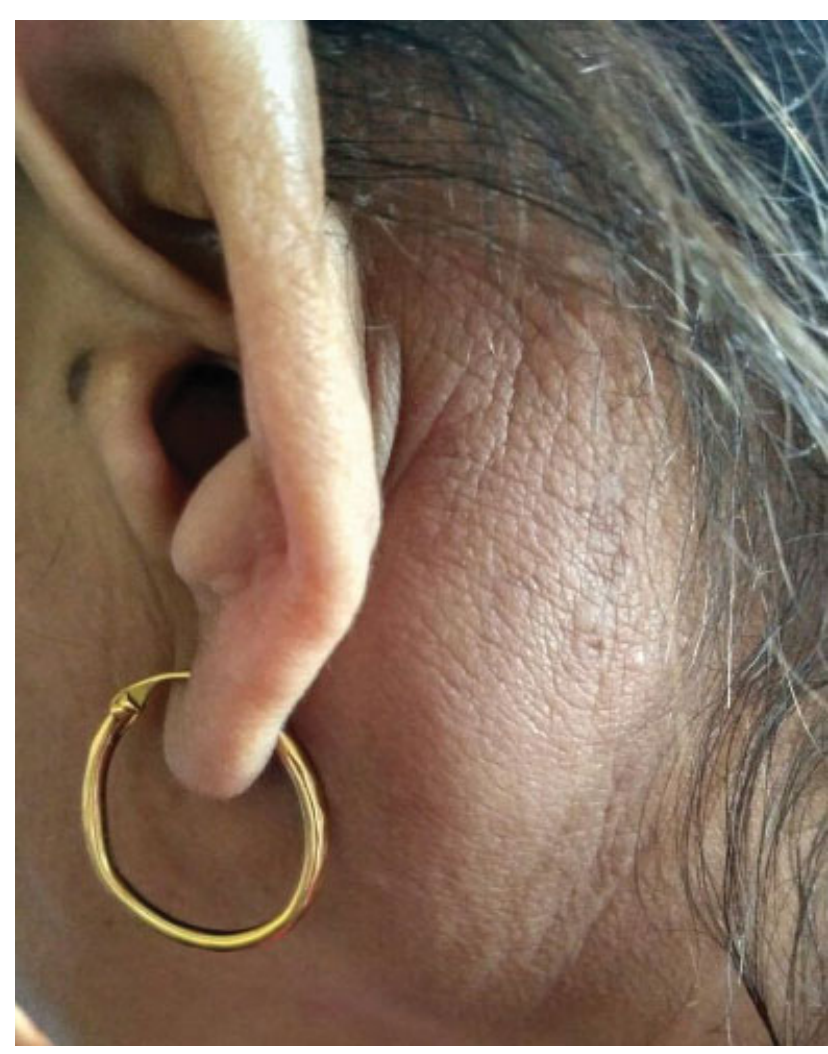

Fig. 1 Preoperative photograph showing postauricular swelling left side.

lymphoid cells with fair numbers of eosinophils forming a collection. A fair number of hyalinized blood vessels were seen. Features were suggestive of KD ( - Figs. 2 and $\mathbf{3}$ ). There was no recurrence in 1-year follow-up.

\section{Discussion}

KD commonly presents with painless subcutaneous masses of insidious onset with lymphadenopathy in the head and

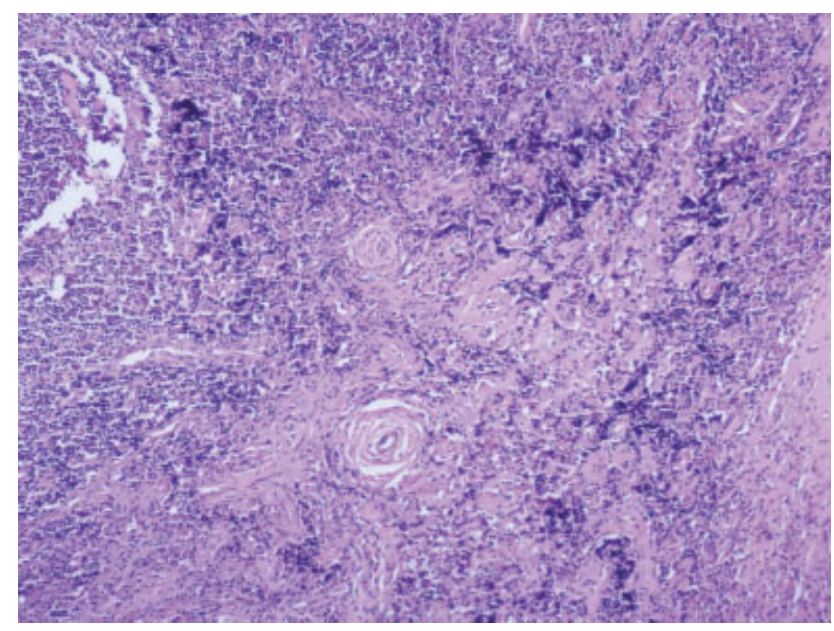

Fig. 2 Histopathological picture of Kimura's disease $(H \& E \times 10$ magnification). Showing fibromuscular tissue with interspersed lobules of polymorphous population of lymphoid cells with fair numbers of eosinophils forming collection. Fair number of hyalinized blood vessels seen. Features were suggestive of Kimura's disease.

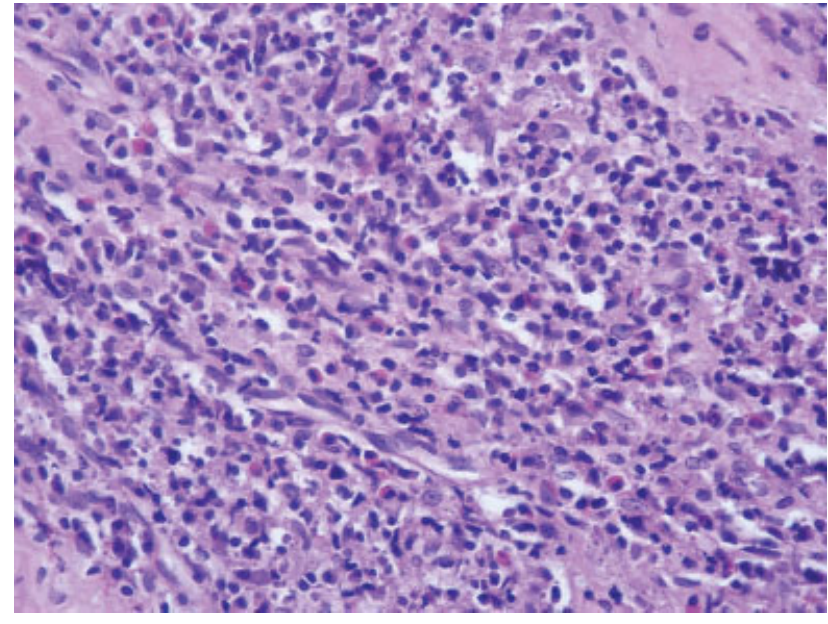

Fig. 3 Histopathological picture of Kimura's disease (H\&E $\times 40$ magnification). Showing fibromuscular tissue with interspersed lobules of polymorphous population of lymphoid cells with fair numbers of eosinophils forming collection. Fair number of hyalinized blood vessels seen. Features were suggestive of Kimura's disease.

neck region. It occasionally affects periauricular, axillary, epitrochlear, or inguinal nodes. In the second and third decades of life, the clinical triad of a subcutaneous nodule in the head and neck region, prominent peripheral eosinophilia, and highly elevated IgE is highly suggestive of KD, although it can become apparent at any age. ${ }^{6}$

$\mathrm{KD}$ clinical course is commonly benign and self-limiting. It may be complicated by renal involvement. In 12 to $16 \%$ of cases, proteinuria may occur. The most common presentation is nephrotic syndrome. ${ }^{7}$ A broad spectrum of histological lesions, such as minimal change disease or mesangioproliferative glomerulonephritis, membranous nephropathy, focal segmental glomerulosclerosis, IgA nephropathy, and IgM nephropathy, has been described to be associated with it. The lesions of KD usually precede the development of renal disease. Sometimes, it may present with renal involvement as initial presentation, before the appearance of subcutaneous lesions, leading to delay in diagnosis. ${ }^{8}$ In our patient, renal functions were normal with no evidence of proteinuria.

The etiopathogenesis of KD is unclear, although it might be a self-limited autoimmune or allergic response triggered by an unknown stimulus. It has been postulated that a parasitic or viral trigger may alter T-cell immunoregulation or induce an IgE-mediated type-1 hypersensitivity resulting in the release of eosinophiliotrophic cytokines. ${ }^{8-10}$

The differential diagnosis of KD is extensive and includes angiolymphoid hyperplasia with eosinophilia, Hodgkin's lymphoma, angioimmunoblastic T-cell lymphoma, Castleman's disease, florid follicular hyperplasia, Langerhans' cell histiocytosis, dermatopathic lymphadenopathy, lymphadenopathy of drug reactions, and parasitic lymphadenitis. ${ }^{1}$

There is no consensus in the treatment of KD. Various treatment methods have been tried with variable results. Excision of the mass is the treatment of choice if the whole lesion can be removed, but local recurrence is common. Localized initial recurrence can be managed with repeated surgical excision. Systemic steroids may be indicated in cases 
complicated by nephrotic syndrome or frequent relapses. Radiation may be considered in cases refractory to surgical and medical therapy for recalcitrant and large tumors. ${ }^{11}$

Cyclosporine, all-transretinoic acid with prednisolone, oral pentoxifylline, leflunomide, imatinib, vincristine, and azathioprine have been tried in the management for KD with variable results. ${ }^{12}$ The choice of treatment method should be individualized. But unfortunately, recurrence is common almost with all the methods of treatment.

\section{Conclusion}

KD is a rare chronic inflammatory disease commonly occurring in males. Although it is a rare disorder, it may be suspected in a patient with slowly progressive head and neck swelling or lymphadenopathy with eosinophilia or high IgE level. It is a distinctive clinicopathologic entity with variable responses to various treatment modalities. We present this impressive clinically entity in a young Indian female to add another case into the literature.

Conflict of Interest

None declared.

\section{References}

1 Chen H, Thompson LD, Aguilera NS, Abbondanzo SL. Kimura disease: a clinicopathologic study of 21 cases. Am J Surg Pathol 2004;28(04):505-513
2 Kimura T, Voshimura S, Ishikawa E. On the unusual granulation combined with hyperplastic changes of lymphatic tissues. Trans Soc Pathol Jpn 1948;37:170-180

3 Baidya DK, Chhabra A, Raj R. Anesthetic management of a patient with Kimura's disease for superficial parotidectomy. J Anaesthesiol Clin Pharmacol 2011;27(03):383-385

4 Abhay H, Swapna S, Darshan T, Vishal J, Gautam P. Kimura's disease: a rare cause of local lymphadenopathy. Int J Sci Stud 2014;2:122-125

5 Rao K, Kumar S. Kimura's disease - a rare cause of head and neck swelling. Int J Otolaryngol Head Neck Surg 2014; 3:200-204

6 Som PM, Biller HF. Kimura disease involving parotid gland and cervical nodes: CT and MR findings. J Comput Assist Tomogr 1992; 16(02):320-322

7 Atar S, Oberman AS, Ben-Izhak O, Flatau E. Recurrent nephrotic syndrome associated with Kimura's disease in a young nonOriental male. Nephron 1994;68(02):259-261

8 Rajpoot DK, Pahl M, Clark J. Nephrotic syndrome associated with Kimura disease. Pediatr Nephrol 2000;14(06):486-488

9 Armstrong WB, Allison G, Pena F, Kim JK. Kimura's disease: two case reports and a literature review. Ann Otol Rhinol Laryngol 1998;107(12):1066-1071

10 Chusid MJ, Rock AL, Sty JR, Oechler HW, Beste DJ. Kimura's disease: an unusual cause of cervical tumour. Arch Dis Child 1997;77(02):153-154

11 Itami J, Arimizu N, Miyoshi T, Ogata H, Miura K. Radiation therapy in Kimura's disease. Acta Oncol 1989;28(04):511-514

12 Li TJ, Chen XM, Wang SZ, Fan MW, Semba I, Kitano M. Kimura's disease: a clinicopathologic study of 54 Chinese patients. Oral Surg Oral Med Oral Pathol Oral Radiol Endod 1996;82(05): 549-555 